\title{
Reseña de Libro
}

Sánchez-Velásquez, L., J. Galindo-González y F. Díaz-Fleischer (eds.). 2008. Ecología, manejo y conservación de los ecosistemas de montaña en México. Comisión Nacional Para el Conocimiento y Uso de la Biodiversidad, Universidad Veracruzana, Mundi Prensa México, S. A., México, D.F. 393 pp. + 16 ilustraciones. ISBN 978-968-7462-57-8.

Esta obra se deriva del Primer Simposio en Ecología, Manejo y Conservación de los Ecosistemas de Montaña en México. Por lo tanto está escrito por 57 autores o coautores pertenecientes a 22 instituciones en su mayoría mexicanas pero algunas de otros países. La obra consta de una Introducción y 18 capítulos distribuidos en tres partes: I. Ecología y manejo (10 capítulos); II. Servicios Ecosistémicos (4 capítulos) y III. Biotecnología (4 capítulos).

En el libro se dan bases ecológicas para la generación de modelos de restauración y aprovechamiento de diferentes bosques mexicanos que se desarrollan en los ecosistemas de montaña. Se presenta información importante para realizar una red de experimentos a lo largo y ancho del país, para el manejo de los recursos maderables y no maderables. Pero yo diría que esa información ya permite instrumentar acciones que conduzcan a un manejo más apropiado de los ecosistemas montañosos, en particular de sus bosques.

Aunque muchos libros y publicaciones han tratado los temas de la ecología y el manejo de los recursos naturales, este es el primero, por lo menos en México, en abordarlos con un "enfoque de montaña", es decir, dar a entender que las montañas son en sí mismas sistemas que tienen que ser estudiados, primero, y apropiadamente manejados después, considerando sus componentes y sus relaciones con otros sistemas y la biosfera.

En México, las sierras y los cerros cubren aproximadamente tres cuartas partes del territorio nacional, representando regiones de alto valor en la producción de madera para las industrias de la construcción, de la celulosa y papel; en la captura, almacenamiento y abastecimiento de agua dulce, así como en la captura de carbono, la conservación de la biodiversidad y la recreación, entre otros.

Tras leer el libro, nadie puede negar la importancia de los ecosistemas de montaña para la economía mexicana y el bienestar ciudadano. Los múltiples servicios ambientales hidrológicos proporcionados por los bosques y selvas de las montañas incluyen la captación de agua y recarga de los mantos acuíferos, la minimización de la erosión de suelos y contaminación de los ríos, así como la regulación del clima 
regional. Dadas las estrechas relaciones que existen entre el agua y los ecosistemas boscosos, el deterioro o transformación de aún más bosques y selvas en México, tendrá consecuencias importantes para el bienestar socio-económico. Así, junto con el cambio climático global, este tipo de deterioro ambiental parece estar vinculado al aumento de daños debido a inundaciones y otros desastres hidrometeorológicos, que en México han causado daños estimados en $\$ 4,547$ millones de dólares durante los últimos 20 años.

Se abordan diferentes aspectos sobre la ecología o el manejo de varios tipos de bosques como son: bosques de pino, bosques de pino-encino, bosques mesófilos de montaña, bosque de oyamel, bosque tropical caducifolio, bosque tropical húmedo. Sin embargo, predominan los capítulos que tratan sobre el bosque mesófilo de montaña.

Se trata de un libro técnico, pero escrito con lenguaje accesible y redacción sencilla. Salvo unos cuantos casos, la información esencial puede ser entendida por lectores no especialistas en el tema tratado. Cada capítulo está organizado con un formato de texto científico, e incluye: resumen, palabras clave, introducción, desarrollo del tema (métodos, resultados y su discusión), una sección final de conclusiones, literatura citada y apéndices (cuando procede).

He disfrutado este libro porque me confirma que la forma más eficiente de alcanzar un manejo duradero y socialmente justo de los recursos naturales es fundamentar las acciones en sólidos conocimientos científicos. En el mismo se parte de diferentes enfoques y escalas de aplicación del conocimiento, desde la respuesta individual de estadios de crecimiento de las plantas a condiciones ambientales hasta la gestión de grandes áreas y regiones, lo que implica una variedad de métodos y técnicas que abarca desde revisiones bibliográficas, observaciones en el terreno, encuestas semiestructuradas, experimentos de campo y jardín, modelos matriciales, técnicas multivariantes de ordenación y uso de sistemas geográficos de información, hasta el manejo de técnicas de cultivo de tejidos y de genética molecular.

Entre los procedimientos usados destacan: la aplicación del conocimiento de la sucesión y los requerimientos ecológicos de especies nativas, en peligro de extinción o de alto valor de uso, para la rehabilitación y restauración de bosques; el análisis de gran escala (por ejemplo la identificación de 60 montañas prioritarias para la gestión forestal y la metodología para identificar municipios y cuencas para el pago por servicios ambientales hidrológicos); y la aplicación tecnológica que utiliza organismos vivos o sus derivados para modificar productos o procesos con un propósito en particular, algo novedoso en libros sobre manejo de recursos. 
La literatura citada al final de cada capítulo constituye una excelente recopilación de referencia, que será un punto útil de partida para nuevos proyectos de investigación y acción a realizar por estudiantes y manejadores. No tengo duda que esta obra será una referencia obligada en los siguientes años.

Por otro lado, me habría gustado ver un capítulo final de síntesis de las diferentes contribuciones, escrito quizás por los editores, que permitiera tener una visión integral de la situación actual de la ecología y manejo de los ecosistemas de montaña y que orientara estudios y acciones futuras para el manejo y conservación de los mismos.

Sólo hay algo, en mi opinión, que pudo ser mejor: la colocación de las ilustraciones a color, en especial de los mapas, al final del libro no es muy cómoda, pues éstas son muy importantes para la buena comprensión de algunos de los capítulos.

Muy por encima de estos detalles y concluyendo, la calidad y actualidad de la información plasmada y la visión integral de editores y autores sobre el manejo de los ecosistemas montañosos de México, son los grandes méritos de esta obra. Recomiendo a académicos y público en general que lo lean.

Vinicio Sosa Fernández. Instituto de Ecología, A.C. Carretera antigua a Coatepec 351, El Haya, Xalapa 91070, Veracruz, México. 